\title{
Níveis de suplemento à base de fubá de milho para novilhos Nelore terminados a pasto na seca: desempenho, características de carcaça e avaliação do pasto
}

\author{
Carlos Eduardo Sverzut Baroni ${ }^{1}$, Rogério de Paula Lana ${ }^{2}$, Antonio Bento Mancio ${ }^{3}$, Augusto \\ César de Queiroz ${ }^{3}$, Maria Ignez Leão ${ }^{3}$, Cláudio Bianor Sverzut ${ }^{4}$
}

\footnotetext{
1 Programa de Pós-graduação em Zootecnia - Departamento de Zootecnia - UFV, CEP: 36.571-000, Viçosa, MG.

2 Departamento de Zootecnia - UFV. Bolsista 1B do CNPq.

${ }^{3}$ Departamento de Zootecnia - UFV.

${ }^{4}$ Faculdade de Engenharia Agrícola - UNICAMP
}

RESUMO - Objetivou-se com este trabalho avaliar a disponibilidade dos componentes da pastagem, o ganho de peso e as características de carcaça de novilhos Nelore recebendo suplemento na fase de terminação durante o período seco. O experimento foi realizado em pastagem de capim-braquiária (Brachiaria brizantha, cv. Marandu), em seis piquetes de 9 hectares. Utilizaram-se 48 novilhos com 30 meses e peso inicial de $412 \pm 16 \mathrm{~kg}$, distribuídos ao acaso em seis lotes de oito animais. Cada lote foi alojado em um piquete e pesado no início e a cada 21 dias, durante 84 dias. Os suplementos foram fornecidos nos níveis de 0,$25 ; 0,5 ; 1,0 ; 2,0$; e 4,0 kg/animal.dia em comparação a um suplemento controle, com apenas mistura mineral. Os suplementos, à exceção do controle, apresentaram níveis variáveis de proteína bruta (87,4 a 25,0\% da matéria seca) e 25:25:50, 15:15:70, 10:10:80, 5:5:90 e 2,5:2,5:95 para 0,25; 0,5; 1,0; 2,0; e 4,0 kg/animal.dia, respectivamente, uma vez que a ureia foi usada como controladora do consumo de suplemento. O delineamento foi inteiramente casualizado e os níveis de suplementação foram avaliados por análise de regressão. A proporção de colmo e folha seca aumentou no decorrer dos períodos experimentais, caracterizando déficit hídrico da estação seca. Houve efeito linear crescente dos níveis de suplemento sobre o peso vivo final, o ganho de peso médio diário e o ganho médio por período, tanto em relação ao consumo de suplemento quanto em relação ao consumo de proteína bruta e nutrientes digestíveis totais. Os níveis de suplemento têm efeito linear crescente sobre o peso de carcaça e a espessura de gordura subcutânea e efeito quadrático sobre o rendimento de carcaça.

Palavras-chave: braquiária, energia, ganho de peso, milho, rendimento de carcaça

\section{Levels of corn meal based supplement in Nellore steers finished on pasture in the dry season: performance, carcass characteristics and pasture evaluation}

\begin{abstract}
The objective of this study was to evaluate the availability of pasture components, average daily gain and carcass characteristics of Nellore steers receiving supplements in the finishing phase during the dry season. The experiment was carried out on Brachiaria brizantha, cv. Marandu pasture, in six nine-hectare paddocks. Forty-eight 30 month old Nellore steers with $412 \pm 16 \mathrm{~kg}$ initial weight were randomly distributed in six groups of eight animals. Each group was placed in a paddock and was weighed at the beginning and at every 21 days, for 84 days. Increasing levels of supplements were used: $0.25,0.5,1.0,2.0$, and $4.0 \mathrm{~kg} /$ animal.day, in comparison to a supplement control that received only mineral mixture. The supplements, except the control, presented variable levels of crude protein (87.4 to $25.0 \%$ of the dry matter), and proportions of mineral mixture:urea:corn meal of 25:25:50, 15:15:70, 10:10:80, 5:5:90, and 2.5:2.5:95 for 0.25, 0.5, $1.0,2.0$, and $4.0 \mathrm{~kg} /$ animal.day, respectively, since that urea was used as supplement intake controller. The supplementation levels were evaluated by regression in a randomized complete design. The proportion of stem and dead leaf increased over the experimental periods, characterizing the dry season. There was increasing linear effect on the final live weight, average daily gain and average daily gain per period as a function of the supplement intake, and average daily gain as a function of the crude protein and intake of total digestible nutrients. The supplement levels have an increasing linear effect on the carcass weight and fat thickness and quadratic effect for carcass yield.
\end{abstract}

Key Words: average daily gain, Brachiaria, carcass yield, corn, energy 


\section{Introdução}

Bovinos mantidos em pastagens de gramíneas tropicais, especialmente durante a época seca, geralmente sofrem deficiências nutricionais de proteína, energia, minerais e vitaminas, devido à estacionalidade de produção das pastagens. Assim, a melhoria da produtividade na criação a pasto presume a utilização de fontes de nitrogênio solúvel, proteína verdadeira, energia, minerais e vitaminas (Paulino \& Ruas, 1988).

Segundo Minson (1990), o valor nutritivo das gramíneas tropicais é baixo no período da seca, pois a maioria não atinge o valor mínimo de 7,0\% de proteína bruta, o que limita o desenvolvimento dos microrganismos do rúmen, a digestibilidade e o consumo da forragem, resultando em baixo desempenho dos animais. Para aumento da utilização da forragem de baixa qualidade, é necessário suprir as deficiências nutricionais dos microrganismos ruminais, favorecendo sua taxa de crescimento e a extração de energia a partir dos carboidratos presentes na forragem, com consequente aumento na produção de ácidos graxos voláteis (Leng, 1990), condição que pode ser alcançada com a utilização de suplementos múltiplos.

A formulação de suplementos para atender determinado desempenho depende não só dos níveis de suplementação, mas também de sua composição, em especial de proteína bruta e energia. Lana (2005a) relatou que, quanto menor o valor nutritivo da pastagem, como ocorre nas pastagens tropicais no período da seca, maior a resposta animal à correção da subnutrição, como pode ser chamado o desempenho acelerado ao baixo uso de concentrado.

Durante o crescimento e a engorda dos animais, as taxas de síntese dos tecidos alteram a composição física e química da carcaça, influenciadas principalmente pela idade, pelo estádio fisiológico, pela nutrição, pelo genótipo e pelo sexo do animal (Berg \& Butterfield, 1979). Uma carcaça é considerada superior quando apresenta quantidade máxima de musculatura, mínima de ossos e camada adequada de gordura, que varia segundo os desejos do consumidor. $\mathrm{O}$ nível de ingestão de nutrientes digestíveis pode afetar a composição da carcaça e o maior efeito é observado na proporção de gordura (Luchiari Filho, 2000).

A relação folha/colmo constitui importante característica na avaliação da qualidade de materiais forrageiros (Pereira et al., 2000), uma vez que maior proporção de folhas pode evidenciar material de melhor degradabilidade, em virtude da menor presença de tecidos estruturais indigestíveis ou de difícil degradação, podendo influenciar a dinâmica e a velocidade da degradação da MS pelos microrganismos do rúmen (Mello et al., 2006).
Conforme Corsi \& Nascimento Jr. (1986), os bovinos só atingem produções elevadas quando consomem quantidades adequadas de alimentos de alta qualidade. Para que isso ocorra em regime de pastejo, há necessidade de grande disponibilidade e proporção de folhas verdes na pastagem.

Os objetivos neste trabalho foram avaliar o desempenho produtivo e as características de carcaça de novilhos Nelore recebendo diferentes níveis de suplemento à base de fubá de milho na fase de terminação durante o período seco e avaliar as características bromatológicas e a disponibilidade total e dos componentes da pastagem.

\section{Material e Métodos}

O experimento foi conduzido na Fazenda Vale do Sonho, localizada no município de Araguaiana, Mato Grosso, cuja coordenada geográfica é $15^{\circ} 8^{\prime} 44^{\prime \prime}$ de latitude Sul e 5152'36" de longitude Oeste. O clima predominante da região é o tropical quente com precipitação anual média de $1.480 \mathrm{~mm}$. O trabalho foi desenvolvido durante o período da seca, entre os meses de julho e outubro.

Foram utilizados 48 novilhos da raça Nelore (seis lotes de oito animais), castrados, com idade e pesos iniciais, respectivamente, de 30 meses e $412 \pm 16 \mathrm{~kg}$, para avaliação do desempenho.

A área experimental destinada aos animais de desempenho foi constituída de seis piquetes de 9 ha, cobertos uniformemente com Brachiaria brizantha cv. Marandu, providos de cochos de duplo acesso e um bebedouro central de alvenaria. Foram avaliados suplementos constituídos de milho (grão triturado), farelo de soja, ureia, sulfato de amônio, mistura mineral e suplemento comercial (Tabela 1). Os suplementos foram fornecidos diariamente em comedouro conjunto, às $8 \mathrm{~h}$, a fim de reduzir o efeito substitutivo sobre o comportamento de ingestão da forragem (Adams, 1985). Foram utilizados níveis crescentes de suplementos ( 0,$25 ; 0,5 ; 1,0 ; 2,0 ;$ e 4,0 kg/animal/dia) em comparação à suplementação com apenas mistura mineral. Os níveis de ureia e sal mineral foram adicionados de forma a permitir o autocontrole de consumo de suplemento pelos animais na quantidade desejada.

As pesagens dos animais foram realizadas a cada 21 dias e seguidas da rotação dos animais e suplementos entre os piquetes, visando à eliminação de possíveis efeitos de piquetes sobre os suplementos. O ganho de peso total foi determinado pela diferença entre o peso inicial e final, após jejum hídrico e alimentar por 18 horas, com o objetivo de reduzir possíveis diferenças no enchimento do trato digestivo (Escuder, 1975). 
Tabela 1 - Composição em ingredientes e nutricional dos suplementos

\begin{tabular}{|c|c|c|c|c|c|c|}
\hline & & & supler & $\mathrm{kg} / \mathrm{anim}$ & & \\
\hline & 0,00 & 0,25 & 0,50 & 1,0 & 2,0 & 4,0 \\
\hline Ingredientes (\% matéria natural) & & & & & & \\
\hline Fubá de milho & - & 48,8 & 70 & 40,8 & 62,5 & 75,2 \\
\hline Ureia/sulfato de amônia & - & 24 & 14 & 7,1 & 3,6 & 1,8 \\
\hline Mistura mineral comercial ${ }^{1}$ & 100 & 22 & 13,4 & - & - & - \\
\hline Sal $(\mathrm{NaCl})$ & - & 4,4 & 2,2 & 1,1 & 0,6 & 0,3 \\
\hline Nutriente & & & & & & \\
\hline Matéria seca (\%) & - & 88,3 & 93,2 & 92,1 & 94,6 & 95,4 \\
\hline Proteína bruta (\%MS) & - & 87,4 & 56,3 & 42,6 & 29,5 & 25,0 \\
\hline Extrato etéreo (\%MS) & - & 2,1 & 3,1 & 6,1 & 7,6 & 8,7 \\
\hline Fibra em detergente neutro (\%MS) & - & 23,6 & 20,8 & 41,9 & 41,7 & 46,5 \\
\hline Fibra em detergente ácido (\%MS) & - & 4,1 & 4,0 & 5,9 & 5,6 & 6,1 \\
\hline
\end{tabular}

Antes do início da suplementação alimentar, todos os animais foram submetidos ao controle de ecto e endoparasitas e desverminados com Moxidectina a $1 \%$.

A coleta do pasto foi realizada no primeiro dia experimental e a cada 21 dias (duração de cada período), num total de 84 dias de duração do experimento, totalizando quatro períodos experimentais. A amostragem do pasto foi feita por meio de dois métodos. No primeiro método, realizou-se o corte de dez áreas delimitadas por um quadrado metálico de $0,5 \times 0,5 \mathrm{~m}\left(0,25 \mathrm{~m}^{2}\right)$, escolhidas aleatoriamente dentro de cada piquete. O corte foi feito rente ao solo (McMeniman, 1997), colhendo-se toda a forragem na área do quadrado. As amostras foram pesadas e divididas em subamostras para formação de amostras compostas e em duplicatas, por piquete e período. De cada par de amostras compostas de forragem, uma foi acondicionada em saco plástico, identificada e congelada, e a outra foi utilizada para separação dos componentes folha verde, colmo verde, folha seca e colmo seco, os quais foram armazenados em sacos plásticos previamente identificados e congelados a $-10{ }^{\circ} \mathrm{C}$ e analisados para determinação das características bromatológicas. No segundo método, utilizou-se o pastejo simulado, como sugerido por Aroeira (1997), pela observação cuidadosa da preferência animal pelas partes da planta ingerida. As amostras foram colhidas pelo mesmo observador, para evitar discrepâncias entre as coletas, e congeladas a $-10{ }^{\circ} \mathrm{C}$ e transportadas para o Laboratório de Nutrição Animal/UFV para realização das análises bromatológicas do material. As amostras foram descongeladas à temperatura ambiente e previamente secas em estufa com ventilação forçada a $60 \pm 5{ }^{\circ} \mathrm{C}$, por 72 horas, quando então foram trituradas em moinho tipo Wiley (conferir grafia) com peneira de $1 \mathrm{~mm}$ e armazenadas em potes de plástico devidamente identificados.

Ao final do último período experimental, os animais foram encaminhados a um frigorífico da região e abatidos. As carcaças foram divididas longitudinalmente na linha dorso-lombar, com auxílio de serra elétrica, e avaliadas quanto ao peso de carcaça quente, à espessura de gordura subcutânea e ao rendimento de carcaça, conforme realizado por Padua et al. (2004). O rendimento de carcaça foi calculado pela razão entre o peso da carcaça quente e o peso vivo em jejum, conforme realizado por Perotto et al. (2000) e Padua et al. (2004). A medida da espessura de gordura subcutânea foi feita por meio de mensurações na altura da $12^{\mathrm{a}}$ costela na meia-carcaça sobre o músculo longissimus dorsi, conforme realizado por Costa et al. (2002) com o uso de um paquímetro Starrett com resolução, exatidão e faixa de 0,05 mm, +0,05 mm e $300 \mathrm{~mm}$, respectivamente.

As determinações de FDN e FDA seguiram os métodos de Van Soest et al. (1991). A quantificação dos carboidratos não-fibrosos (CNF) foi feita de acordo com Weiss (1999):

$\mathrm{CNF}=\mathrm{CT}-\mathrm{FDNcp}$

em que: $\mathrm{CT}$ = carboidratos totais (\%MS); e FDNcp = fibra em detergente neutro isenta de cinzas e proteína (\%MS).

Para estimativas de fibra em detergente ácido indigestível (FDAi), foi adotado o procedimento único, sequencial, adaptando-se as técnicas descritas Cochram et al. (1986), com base na digestibilidade in situ, por 144 horas. 
As determinações da matéria seca potencialmente digestível (MSpd) foram realizadas de acordo com Paulino et al. (2006):

$$
\text { MSpd }(\% \text { MS })=\{0,98 \times(100-\text { FDN })\}+(\text { FDN }- \text { FDNi })
$$
em que: $\mathrm{FDN}=$ fibra em detergente neutro (\%MS); e FDNi = fibra em detergente neutro indigestível (\%MS).

As análises de matéria seca, proteína bruta, extrato etéreo, celulose, lignina e cinzas foram realizadas de acordo com as técnicas descritas por Silva \& Queiroz (2002).

O delineamento foi o inteiramente casualizado (DIC) com seis níveis de suplementos e oito repetições. Cada animal correspondeu a uma unidade experimental e as comparações entre médias de tratamentos foram realizadas por análise de regressão polinomial do programa UFV (2002), adotando-se nível de significância de 5\%.

\section{Resultados e Discussão}

De acordo com Euclides et al. (1998), a disponibilidade de $2.500 \mathrm{~kg}$ de MS por hectare propicia a seletividade animal ao pastejar. Os animais utilizados no experimento foram mantidos em pastagem com elevada disponibilidade de matéria seca ao longo de todo período experimental, no entanto esse fator não foi limitante à seletividade do pasto (Tabela 2).
Com o avanço dos períodos experimentais, a relação folha e colmo verde/seco diminuiu como consequência do estresse hídrico (Tabela 2). Silva et al. (2005) observaram redução nas relações folhas totais por perfilho e também de folhas verdes por perfilho à medida que reduziram a disponibilidade hídrica do solo.

Inúmeros estudos comprovam que bovinos em pastejo selecionam forragem verde em detrimento da forragem morta (Santos et al., 2004a). Euclides et al. (1992) observaram que dietas selecionadas por animais em pastagens tropicais apresentavam em média $90 \%$ de matéria seca verde, enquanto as porcentagens de matéria seca verde disponíveis nas pastagens eram de $26 \%$ para Brachiaria decumbens e de 23\% para Brachiaria humidicola.

A fração folha verde apresentou maiores teores de proteína bruta, proteína indigestível em detergente neutro, proteína indigestível em detergente ácido, extrato etéreo e cinzas e menores teores de fibra que os outros componentes do pasto (Tabela 3). Somente a folha verde apresentou teor de nitrogênio próximo a 1\% da MS. Assim, o consumo de maiores proporções dos outros componentes, além de folha verde, pode resultar em balanço negativo de nitrogênio no rúmen, com consequente redução do consumo de matéria seca pelos animais (Santos et al., 2004a).

Tabela 2 - Disponibilidade (toneladas de MS por hectare) e porcentagem de folha verde, folha seca, colmo verde e colmo seco de capimmarandu nos períodos experimentais

\begin{tabular}{lrrrr}
\hline Item & \multicolumn{1}{c}{ Período 1} & Período 2 & Período 3 & Período 4 \\
\hline Disponibilidade total(t/ha de MS) & $7,93 \pm 1,89$ & $7,42 \pm 1,76$ & $7,18 \pm 1,36$ & $7,01 \pm 1,08$ \\
Folha verde (\%) & $14,81 \pm 6,44$ & $14,49 \pm 6,08$ & $13,02 \pm 3,49$ & $10,14 \pm 5,86$ \\
Folha seca (\%) & $19,61 \pm 5,87$ & $23,24 \pm 4,29$ & $22,74 \pm 7,59$ & $32,99 \pm 8,08$ \\
Colmo verde (\%) & $34,02 \pm 8,58$ & $33,13 \pm 7,73$ & $33,02 \pm 18,13$ & $23,17 \pm 6,35$ \\
Colmo seco (\%) & $31,56 \pm 10,36$ & $29,14 \pm 9,79$ & $31,22 \pm 10,66$ & $33,70 \pm 14,51$ \\
\hline
\end{tabular}

Tabela 3 - Composição nutricional da dieta selecionada pelos bovinos e dos componentes da pastagem de capim-marandu

\begin{tabular}{|c|c|c|c|c|c|}
\hline$\overline{\text { Item }^{1}}$ & Pastejo simulado & Folha verde & Folha seca & Colmo verde & Colmo seco \\
\hline Matéria seca (\%) & 51,32 & 45,97 & 55,88 & 48,52 & 68,53 \\
\hline Proteína bruta (\% MS) & 5,30 & 6,47 & 3,26 & 3,66 & 2,60 \\
\hline Proteína insolúvel em detergente neutro (\% MS) & 1,54 & 2,89 & 1,71 & 1,22 & 1,60 \\
\hline Proteína insolúvel em detergente ácido (\% MS) & 0,83 & 1,17 & 0,58 & 0,61 & 0,79 \\
\hline Extrato etéreo (\% MS) & 1,67 & 1,73 & 1,29 & 0,82 & 0,77 \\
\hline Fibra em detergente neutro (\% MS) & 73,89 & 78,53 & 81,31 & 88,06 & 88,29 \\
\hline Fibra em detergente ácido (\% MS) & 38,17 & 42,35 & 43,77 & 58,80 & 57,39 \\
\hline FDNcp (\% MS) & 70,23 & 73,75 & 78,09 & 86,10 & 85,11 \\
\hline FDAcp (\% MS) & 35,34 & 40,37 & 41,73 & 57,66 & 55,80 \\
\hline Fibra em detergente neutro indigestível (\% MS) & 35,12 & 29,47 & 34,73 & 64,99 & 59,92 \\
\hline Fibra em detergente ácido indigestível (\% MS) & 18,32 & 16,44 & 17,60 & 43,60 & 37,83 \\
\hline Celulose (\% MS) & 34,49 & 34,74 & 37,66 & 48,88 & 46,45 \\
\hline Lignina (\% MS) & 6,65 & 6,48 & 5,13 & 14,31 & 10,52 \\
\hline Cinzas (\% MS) & 6,98 & 7,15 & 5,62 & 3,76 & 3,94 \\
\hline Carboidratos totais (\% MS) & 86,04 & 84,66 & 89,83 & 91,74 & 92,68 \\
\hline Carboidratos não-fibrosos (\% MS) & 15,81 & 10,90 & 11,74 & 5,64 & 7,56 \\
\hline
\end{tabular}


Correlacionando a disponibilidade de forragem verde e forragem morta na estação seca, Santos et al. (2004b) observaram que o ganho médio diário de peso dos animais sob suplementação correlacionou-se linear e negativamente com a disponibilidade de forragem morta e linear e positivamente com a disponibilidade de forragem verde. Essas observações evidenciam a importância da disponibilidade e proporção de forragem verde e da proporção de folha verde na pastagem, assim como o efeito negativo da presença de forragem morta.

O consumo de suplemento (Tabela 4) foi muito próximo ao desejado, de forma que a utilização de ureia/ sulfato de amônia e sal comum como limitadores de consumo (Lana, 2005b) foram eficientes em controlar o consumo dos animais.

O fornecimento de suplementos em regime de autocontrole de consumo para animais na fase de recria facilita o manejo e racionaliza a utilização de mão-de-obra na distribuição de suplementos na pastagem, além de evitar que o animal crie dependência do suplemento e apresentar aspectos positivos sob o ponto de vista nutricional (Gomes Jr., 2000).

O ganho médio diário aumentou de forma linear $(\mathrm{P}<0,05)$, e foi menor entre 43 e 84 dias em relação a 1 e 42 dias (Tabela 4). O ganho de peso não foi elevado se considerados para os níveis de suplementação adotados, em decorrência da redução do ganho com o avanço do experimento, associada à piora das condições das pastagens com o avanço do período da seca (Tabelas 2 e 3).

Resultados semelhantes foram obtidos por Baião et al. (2004) em mestiços Nelore no período seco do ano. Esses autores verificaram ganhos de peso de 0,18 e 0,46 kg/ animal.dia para consumos de 1,1 e 2,8 kg/animal.dia de suplemento, respectivamente. A melhora no ganho de peso com a suplementação provavelmente foi ocasionada pelo crescente consumo de nutrientes digestíveis totais (NDT) e proteína bruta (PB) suplementar, sendo que o consumo de
PB variou de 0,16 a 0,77 kg/animal.dia, ou seja, de 0,04 a 0,19\% do peso vivo (Tabela 4). Essa observação está de acordo com Moore et al. (1999), que afirmaram que a resposta à suplementação para ganho de peso é maior quando a suplementação proporciona consumo de proteína bruta maior que $0,05 \%$ do peso vivo, e quando esse consumo for maior que $0,1 \%$ do $P V$ a resposta é positiva.

Ganhos aproximados de 0,500 kg/animal.dia para consumo de suplemento da ordem de 0,9\% PV (Boin \& Tedeschi (1997), o que neste caso representa consumo de $3,5 \mathrm{~kg}$ de suplemento por animal; ganhos desta magnitude foram observados neste experimento. Nos mesmos parâmetros, Bomfim et al. (2001) obtiveram ganhos de 0,41 e 0,65 kg/animal/dia para consumos de suplemento de 2,27 e 4,5 kg/animal.dia, resultados também próximos ao deste trabalho.

El-Memari et al. (2002), em experimento com novilhos Nelore castrados sob pastagens na época seca, forneceram dietas com teores de $25 \%$ de PB e cerca de $70 \%$ de NDT e obtiveram ganhos de 0,489 e 0,630 kg/animal/dia para consumos de suplemento da ordem de 2,6 e 5,2 kg/animal/dia, respectivamente.

O desempenho satisfatório dos animais recebendo apenas mistura mineral $(0,249 \mathrm{~kg} /$ animal/dia) pode ser atribuído ao fato de que a pastagem apresentou elevada disponibilidade de matéria seca e pelo menos $10 \%$ de folhas verdes.

Detmann et al. (2004) trabalharam com novilhos mestiços sob suplementação no período seco do ano e observaram desempenhos semelhantes para os animais que receberam apenas a suplementação mineral, nos quais o ganho médio diário foi de $0,277 \mathrm{~kg} /$ animal.dia.

Considerando o tipo dos animais deste experimento, que são adultos, onde estes não estão mais em fase de crescimento e com peso elevado ao início do experimento, com média de $410 \mathrm{~kg}$, é aceitável que o desempenho seja aquém do esperado (Figura 1). Portanto, esses animais estariam apenas depositando gordura e não mais músculos

Tabela 4 - Desempenho de novilhos Nelore sob suplementação durante o período seco

\begin{tabular}{|c|c|c|c|c|c|c|c|c|c|}
\hline \multirow[b]{2}{*}{ Item } & \multicolumn{6}{|c|}{ Nível de suplemento (kg/animal.dia) } & \multirow[t]{2}{*}{ Regressão $^{1}$} & \multirow[t]{2}{*}{$\mathrm{r}^{2}$} & \multirow[t]{2}{*}{ CV (\%) } \\
\hline & 0,0 & 0,25 & 0,5 & 1,0 & 2,0 & 4,0 & & & \\
\hline Peso vivo inicial (kg) & 422,7 & 399,9 & 404,6 & 410,8 & 408,1 & 413,2 & & & \\
\hline Ganho médio diário (kg) & 0,249 & 0,257 & 0,188 & 0,273 & 0,320 & 0,526 & $Y=0,207+0,0737 * X$ & 0,43 & 39,48 \\
\hline Ganho médio diário 1-42 (kg) & 0,323 & 0,409 & 0,395 & 0,439 & 0,501 & 0,796 & $Y=0,335+0,109 * X$ & 0,45 & 35,08 \\
\hline Ganho médio diário 43-84 (kg) & 0,175 & 0,105 & $-0,02$ & 0,108 & 0,139 & 0,257 & $Y=0,0756+0,0398 * X$ & 0,08 & 150,31 \\
\hline Consumo PB suplementar ${ }^{2}$ & 0,0 & 0,16 & 0,22 & 0,32 & 0,48 & 0,77 & $\mathrm{Y}=0,179+0,379 * \mathrm{CPB}$ & 0,37 & 38,39 \\
\hline
\end{tabular}

$1 \mathrm{X}=$ suplemento em kg. $\mathrm{P}<0,05$.

2Consumo via suplemento estimado pelo programa Sistema Viçosa de Formulação de Rações (Lana, 2005b). 


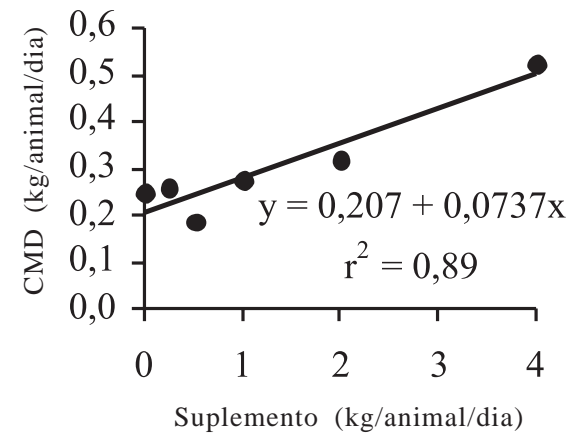

Cada ponto representa a média de oito animais durante 84 dias.

Figura 1 - Ganho de peso diário em novilhos Nelore em terminação recebendo suplemento à base de milho no período seco.

e em fase de crescimento ósseo. Além disso, exigências de proteína menores e as energéticas maiores.

Silva et al. (2002), trabalhando com requisitos energéticos e proteicos de animais Nelore não-castrados, observaram que os conteúdos de gordura e energia no ganho de peso de corpo vazio aumentaram 37 e 17,5\%, respectivamente, com o aumento de 200 para $450 \mathrm{~kg}$ no peso vivo, e que os requisitos proteicos decresceram $6,05 \%$ com o aumento da concentração de gordura em detrimento à de proteína. Do mesmo modo, Berg \& Butterfield, citados por Silva et al. (2002), afirmaram que, à medida que se aumenta o peso corporal, a concentração de gordura se eleva, de forma que as exigências energéticas acompanham este acréscimo, em razão do maior valor energético do ganho com a elevação do peso dos animais.

As conversões de suplemento $(\mathrm{kg} / \mathrm{kg}$ de ganho de peso adicional), obtidas pela recíproca do coeficiente da regressão linear do ganho de peso em função do consumo de suplemento (Figura 1), foram de 13,5:1. A conversão de suplemento em $\mathrm{kg} / \mathrm{kg}$ de ganho de peso de 13,5:1 foi superior à normalmente observada de 10:1, que é típica de suplementação energética (Horn et al., 1995; Bodine et al., 2001).

A relação dos suplementos à base de milho foi pior que a de 10:1 apresentada por Lana (2005a) em pesquisa com análise de dados de 25 experimentos com bovinos em crescimento sob pastejo no período da seca. Essa baixa resposta pode ser devida ao fato de os animais serem adultos em terminação, evidenciando novamente que os adultos são mais responsivos à energia que proteína.

A suplementação afeta positivamente o desempenho dos animais, mas de forma decrescente, devido ao efeito substitutivo (Lana \& Gomes Jr., 2002) e à saturação cinética associada ao aumento do fornecimento de nutrientes (Lana et al., 2005). Desta forma, o ganho de peso proporcionado pela suplementação pode ficar aquém do desejado, por isso, deve-se analisar com critério o objetivo da suplementação, pois essa suplementação pode tornar-se antieconômica. A pecuária moderna visa a obtenção de ganhos de peso mais elevados, à base de altos níveis de suplementação. Entretanto, esse procedimento pode ser desvantajoso, pois quanto maior o consumo de suplemento, pior a conversão de suplementos pelos animais em função da lei dos rendimentos decrescentes (Lana, 2005a). Uma vez que o suplemento onera o custo de produção dos animais, deve ser incluído com critério ao sistema de produção de carne.

$\mathrm{O}$ peso de carcaça quente e a espessura de gordura subcutânea apresentaram comportamento linear $(\mathrm{P}<0,05)$ de acordo com o consumo de suplemento. O rendimento de carcaça, no entanto, apresentou comportamento não-linear $(\mathrm{P}<0,05)$ (Tabela 5).

Moraes (2003) observou valor próximo para rendimento de carcaça, de 51,4\%, em animais consumindo 4,0 kg de suplemento por dia. Moletta \& Perotto (1997) encontraram valor de $54,8 \%$ de rendimento de carcaça em relação ao peso vivo para animais terminados a pasto com idade de 29 meses, próximo também ao deste trabalho. Thiago et al. (2002) reportaram valores semelhantes, da ordem de 54,0\%, para novilhos Pardo-Suíço corte $\times$ Nelore, enquanto Detmann (2002) observou valor de 52,1\% em animais mestiços terminados em pastagem de Brachiaria decumbens durante o período da seca e consumindo $4,0 \mathrm{~kg}$ de suplemento por dia.

O rendimento de carcaça é altamente influenciado pelo peso vivo do animal (Kabeya et al., 2002). Assim, como os animais dos diferentes níveis de suplementos apresentaram

Tabela 5 - Peso de carcaça quente, espessura de gordura subcutânea e rendimento de carcaça de novilhos Nelore terminados no período seco com diversos níveis de suplemento

\begin{tabular}{|c|c|c|c|c|c|c|c|c|c|}
\hline \multirow[b]{2}{*}{ Item } & \multicolumn{6}{|c|}{ Nível de suplemento (kg/animal.dia) } & \multirow[t]{2}{*}{ Regressão $^{1}$} & \multirow[t]{2}{*}{$\mathrm{r}^{2}$} & \multirow[t]{2}{*}{$\mathrm{CV}(\%)$} \\
\hline & 0,0 & 0,25 & 0,5 & 1,0 & 2,0 & 4,0 & & & \\
\hline Peso de carcaça (kg) & 243,1 & 239,6 & 239,9 & 246,5 & 248,6 & 254,6 & $Y=240+3,83 * X$ & 0,21 & 4,31 \\
\hline Espessura de gordura (mm) & 1,88 & 1,88 & 2,00 & 2,00 & 2,12 & 2,12 & $Y=1,92+0,0639 * X$ & 0,09 & 14,38 \\
\hline Rendimento de carcaça ${ }^{1}$ & 54,9 & 56,8 & 56,4 & 56,8 & 57,1 & 55,5 & $Y=55,5+1,72 * X-0,435 * X^{2}$ & 0,63 & 0,89 \\
\hline
\end{tabular}

${ }^{1}$ Em relação ao peso vivo pré-abate.

${ }^{2} \mathrm{X}=$ suplemento, em kg; $\mathrm{P}<0,05$. 
comportamento linear $(\mathrm{P}<0,05)$ para o peso vivo final (Tabela 4), é justificável o mesmo efeito linear $(\mathrm{P}<0,05)$ para a característica rendimento de carcaça (Tabela 5).

Ao trabalharem com níveis de concentrado na dieta de animais zebuínos, Costa et al. (2005) encontraram efeito linear do consumo de suplemento sobre a espessura de gordura subcutânea. Segundo os autores, animais alimentados com rações que contenham maiores níveis energéticos tendem a depositar maior quantidade de gordura em comparação aos animais que recebem dietas com menores níveis de energia, o que pode explicar a maior deposição de gordura subcutânea daqueles que receberam maiores níveis de concentrado.

Contudo, apesar do efeito linear $(\mathrm{P}<0,05)$ do consumo de suplemento sobre a característica espessura de gordura subcutânea em função (Tabela 5), este consumo apresentou coeficiente de variação um pouco elevado e baixo coeficiente de determinação, o que em parte pode ser explicado pela ausência de diferenças marcantes quanto à maturidade fisiológica (terminação) entre os animais dos diferentes tratamentos (Zervoudakis et al., 2001).

\section{Conclusões}

O desempenho de bovinos adultos em terminação em pastagens de capim-marandu durante o período seco aumenta linearmente com os níveis de suplementação. A conversão de suplemento em kg/kg de ganho de peso foi de 13,5:1, típica de suplementação energética. A suplementação de animais adultos em terminação apenas é viável em níveis superiores a 2,0 kg/animal.dia em situações de preços de comercialização favoráveis e insumos mais baratos. A forragem com pelo menos $10 \%$ de folhas verdes e disponibilidade total de MS superior a 2,5 t/ha é eficiente em promover desempenhos satisfatórios em animais na fase de terminação.

\section{Agradecimentos}

À Integral Nutrição Animal, pelo grande apoio e pela parceria para realização deste trabalho.

\section{Referências}

ADAMS, D.C. Effect of time of supplementation on performance, forage intake and grazing behavior or yearling beef steers grazing Russian wild ryegrass in the fall. Journal of Animal Science, v.61, n.4, p.1037-1042, 1985.

AROEIRA, L.J.M. Estimativas de consumo de gramíneas tropicais. In: SIMPÓSIO INTERNACIONAL DE DIGESTIBILIDADE EM RUMINANTES, 1997, Lavras. Anais... Lavras: UFLA-FAEPE, 1997. p.127-164.
BAIÃO, E.A.M.; BAIÃO, A.F.F.; ANDRADE, I.F. et al. Avaliação do desempenho de novilhos mestiço nelore recebendo níveis de suplementação a pasto, no período seco do ano. In: REUNIÃO ANUAL DA SOCIEDADE BRASILEIRA DE ZOOTECNIA, 41. 2004, Campo Grande. Anais... São Paulo: Sociedade Brasileira de Zootecnia, 2004. (CD-ROM).

BERG, R.T.; BUTTERFIELD, R.M. Nuevos conceptos sobre desarrollo de ganado vacuno. Zaragoza: Acribia, 1979. 297p.

BODINE, T.N.; PURVIS II, H.T.; LALMAN, D.L. Effects of supplement type on animal performance, forage intake, digestion, and ruminal measurements of growing beef cattle. Journal of Animal Science, v.79, p.1041-1051, 2001.

BOIN, C.; TEDESCHI, L.O. Sistemas intensivos de produção de carne bovina: II. Crescimento e acabamento. In: SIMPÓSIO SOBRE PECUÁRIA DE CORTE, 4., 1997, Piracicaba. Anais... Piracicaba: Fundação de Estudos Agrários Luiz de Queiroz, 1997. p.205-228.

BOMFIM, M.A.D.; REZENDE, C.A.P.; PAIVA, P.C.A. et al. Níveis de concentrado na terminação de novilhos Holandês x Zebu suplementados a pasto na estação seca. Ciência e Agrotecnologia, v.25, n.6, p.1457-1466, 2001.

COCHRAM, R.C.; ADAMS, D.C.; WALLACE, J.D. et al. Predicting digestibility of different diets with internal markers: Evaluation of four potential markers. Journal of Animal Science, v.63, n.5, p.1476. 1986.

CORSI, M.; NASCIMENTO JR., D. Princípios de fisiologia e morfologia de plantas forrageiras aplicados no manejo das pastagens. In: PEIXOTO, A.M.; MOURA J.C.; FARIA, V.P. (Ed.). Pastagens: fundamentos da exploração racional.1.ed. Piracicaba: Fundação de Estudos Agrários Luiz de Queiroz, 1986. p.11-37.

COSTA, E.C.; RESTLE, J.; VAZ, F.N. et al. Características da carcaça de novilhos Red Angus superprecoces abatidos com diferentes pesos. Revista Brasileira de Zootecnia, v.31, n.1, p.119-128, 2002.

COSTA, M.A.L.; VALADARES FILHO, S.C.; PAULINO, M.F. et al. Desempenho, digestibilidade e características de carcaça de novilhos zebuínos alimentados com dietas contendo diferentes níveis de concentrado. Revista Brasileira de Zootecnia, v.34, n.1, p.268-279, 2005.

DETMANN, E. Níveis de proteína bruta em suplementos múltiplos para terminação de bovinos em pastejo: Desempenho produtivo, simulação e validação de parâmetros da cinética digestiva. 2002. 83f. Tese (Doutorado em Zootecnia) - Universidade Federal de Viçosa, Viçosa, MG.

DETMANN, E.; PAULINO, M.F.; ZERVOUDAKIS, J.T. et al. Níveis de proteína bruta em suplementos múltiplos para terminação de novilhos mestiços em pastejo durante a época seca: desempenho produtivo e características de carcaça. Revista Brasileira de Zootecnia, v.33, n.1, p.169-180, 2004.

EL-MEMARI, A.C.; ZEOULA, L.M.; PRADO, I.N. et al. Suplementação de novilhos nelore em pastejo de brachiaria brizantha com diferentes níveis e fontes de concentrados. In: REUNIÃO ANUAL DA SOCIEDADE BRASILEIRA DE ZOOTECNIA, 39., 2002, Recife. Anais... Recife: Sociedade Brasileira de Zootecnia, 2002. (CD-ROM).

ESCUDER, J. Experimento com animais em pastejo. Revista da Sociedade Brasileira de Zootecnia, v.4, p.158-176, 1975.

EUCLIDES, V.P.B.; MACEDO, M.C.M.; OLIVEIRA, M.P. Avaliação de diferentes métodos de amostragem [para se estimar o valor nutritivo de forragens] sob pastejo. Revista Brasileira de Zootecnia, v.21, n.4, p.691-701, 1992.

EUCLIDES, V.P.B.; EUCLIDES FILHO, K.; ARRUDA, Z.J. et al. Desempenho de novilhos em pastagens de Brachiaria decumbens submetidos a diferentes regimes alimentares. Revista Brasileira de Zootecnia, v.27, n.2, p.246-254, 1998.

GOMES JR., P. Composição químico-bromatológicas da Brachiaria decumbens e desempenho de novilhos em recria suplementados durante a época seca. 2000. 66f. Dissertação (Mestrado em Zootecnia). Universidade Federal de Viçosa, Viçosa, MG. 
HORN, G.W.; CRAVEY, M.D.; McCOLLUM, F.T. et al. Influence of high-starch vs high-fiber energy supplements on performance of stocker cattle grazing wheat pasture and subsequent feedlot performance. Journal of Animal Science, v.73, p.45-54, 1995.

KABEYA, K.S.; PAULINO, M.F.P.; DETAMANN, E. et al. Suplementação de novilhos mestiços em pastejo na época de transição água-seca: Desempenho produtivo, características físicas de carcaça, consumo e parâmetros ruminais. Revista Brasileira de Zootecnia, v.31, n.1, p.213-222, 2002.

LANA, R.P. Nutrição e alimentação animal (mitos e realidades). Viçosa, MG: Universidade Federal de Viçosa, 2005a. 344p.

LANA, R.P. Sistema Viçosa de formulação de rações. Viçosa, MG: Universidade Federal de Viçosa, 2005b. 91p.

LANA, R.P.; GOES, R.H.T.B.; MOREIRA, L.M. et al. Application of Lineweaver-Burk data transformation to explain animal and plant performance as a function of nutrient supply. Livestock Production Science, v.98, p.219-224, 2005.

LANA, R.P.; GOMES JR. P. Sistema de suplementação alimentar para bovinos de corte em pastejo. Validação. Revista Brasileira de Zootecnia, v.31, n.1, p.451-459, 2002 (supl.).

LENG, R.A. Factors affecting the utilization of "poor-quality" forages by ruminants particularly under tropical conditions. Nutrition Research Review, v.3, n.3, p.277- 303, 1990.

LUCHIARI FILHO, A. Pecuária da carne bovina. 1.ed. São Paulo: LinBife, 2000. 134p.

McMENIMAN, N.P. Methods of estimating intake of grazing animals. In: CAMPOS, O.F.; LIZIERE, R.S.; FIGUEIREDO, E.A.P. (Eds.). Simpósio sobre tópicos especiais em zootecnia. Juiz de Fora: Sociedade Brasileira de Zootecnia, 1997, p.131-168.

MELLO, A.C.L.; LIRA, M.A.; DUBEUX JR., J.C.B. et al. Degradação ruminal da matéria seca de clones de capim-elefante em função da relação folha/colmo. Revista Brasileira de Zootecnia, v.35, n.4, p.1316-1322, 2006.

MINSON, D.J. Forage in ruminant nutrition. New York: Academic Press, 1990. 83p.

MOLETTA, J.L.; PEROTTO, D. Efeito do manejo alimentar no pré e/ou pós desmame, sobre o desempenho e características de carcaça de novilhos. In: REUNIÃO ANUAL DA SOCIEDADE BRASILEIRA DE ZOOTECNIA, 34., 1997, Juiz de Fora. Anais... Juiz de Fora: Sociedade Brasileira de Zootecnia, 1997. (CD-ROM)

MOORE, J.E.; BRANT, M.H.; KUNKLE, W.E. et al. Effects of supplementation on voluntary forage intake, diet digestibility, and animal performance. Journal of Animal Science, v.77, p.122-135, 1999 (suppl. 2).

MORAES, E.H.B.K. Suplementos múltiplos para recria e terminação de novilhos mestiços em pastejo durante os períodos de seca e transição seca-águas. 2003. $70 \mathrm{f}$. Dissertação (Mestrado em Zootecnia) - Universidade Federal de Viçosa, Viçosa, MG.

PADUA, J.T.; MAGNABOSCO, C.U.; SAINZ, R.D. et al. Genótipo e condição sexual no desempenho e nas características de carcaça de bovinos de corte superjovens. Revista Brasileira de Zootecnia, v.33, n.6, p.2330-2342, 2004 (supl. 3).

PAULINO, M.F.; RUAS, J.R.M. Considerações sobre recria de bovinos de corte. Informe Agropecuário, v.13, n.153/154, p.68-79, 1988 .
PAULINO, M.F.; DETMANN, E.; VALADARES FILHO, S.C. Suplementação animal em pasto: Energética ou protéica? In: SIMPÓSIO SOBRE MANEJO ESTRATÉGICO DA PASTAGEM, 3., Viçosa, MG, 2006. Anais... Viçosa, MG, 2006. p.359-392.

PEREIRA, A.V.; FERREIRA, R.P.; PASSOS, L.P. et al. Variação da qualidade de folhas em cultivares de capim-elefante (Pennisetum purpureum) e híbridos de capim-elefante $\mathrm{x}$ milheto ( $P$. purpureum x $P$. glaucum), em função da idade da planta. Ciência e Agrotecnologia, v.24, n.2, p.490-499, 2000

PEROTTO, D.; MOLETTA, J.L.; CUBAS, A.C. Características quantitativas da carcaça de bovinos Charolês, Caracu e cruzamentos recíprocos terminados em confinamento. Revista Brasileira de Zootecnia, v.29, n.1, p.117-124, 2000.

SANTOS, E.D.G.; PAULINO, M.F.; QUEIROZ, D.S. et al. Avaliação de pastagem diferida de Brachiaria decumbens Stapf: 1. Características químico bromatológicas da forragem durante a seca. Revista Brasileira de Zootecnia, v.33, n.1, p.203-213, 2004a.

SANTOS, E.D.G.; PAULINO, M.F.; VALADARES FILHO, S.C. et al. Terminação de tourinhos limousin $\mathrm{x}$ nelore em pastagem diferida de Brachiaria decumbens Stapf, durante a estação seca, alimentados com diferentes concentrados. Revista Brasileira de Zootecnia, v.33, n.6, p.1627-1637, 2004b.

SILVA, D.J.; QUEIROZ, A.C. Análise de alimentos: Métodos químicos e biológicos. 3.ed. Viçosa, MG: UFV, Imprensa universitária, 2002. 165p.

SILVA, F.F.; VALADARES FILHO, S.C.; ITAVO, L.C.V. et al. Composição corporal e requisitos energéticos e protéicos de bovinos nelore, não-castrados, alimentados com rações contendo diferentes níveis de concentrado e proteína. Revista Brasileira de Zootecnia, v.31, n.1, p.503-513, 2002 (supl.)

SILVA, M.M.P.; VASQUEZ, H.M.; BRESSAN-SMITH, R.E. et al. Respostas morfogênicas de gramíneas forrageiras tropicais sob diferentes condições hídricas do solo. Revista Brasileira de Zootecnia, v.34, n.5, p.1493-1504, 2005.

THIAGO, L.R.L.S.; SILVA, J.M.; FEIJÓ, G.L.D. et al. Engorda de novilhos pardo suíço corte $\mathrm{x}$ nelore em pastagem de $B$. decumbens na seca, recebendo diferentes níveis de concentrado. In: REUNIÃO ANUAL DA SOCIEDADE BRASILEIRA DE ZOOTECNIA, 39. Recife. Anais... Recife: Sociedade Brasileira de Zootecnia, 2002. (CD-ROM)

UNIVERSIDADE FEDERAL DE VIÇOSA - UFV. Sistema de análises estatísticas e genéticas - SAEG. Versão 8.X. Viçosa, MG: 2002. 235p.

VAN SOEST, P.J.; ROBERTSON, J.B.; LEWIS, B.A. Methods for dietary fiber, and nonstarch polysaccharides in relation to animal nutrition. Journal of Dairy Science, v.74, n.10, p.35833597, 1991.

WEISS, W.P. Energy prediction equations for ruminant feeds. In: CORNELL NUTRITION CONFERENCE FOR FEED MANUFACTURES, 61., 1999, Ithaca. Proceedings... Ithaca: Cornell University, 1999. p.176-185.

ZERVOUDAKIS, J.T.; PAULINO, M.F.; DETMANN, E. et al. Desempenho e características de carcaça de novilhos suplementados no período das águas. Revista Brasileira de Zootecnia, v.30, n.4, p.1381-1389, 2001. 